\title{
Role of Corticotropin-Releasing Factor (CRF) Receptor-1 on the Catecholaminergic Response to Morphine Withdrawal in the Nucleus Accumbens (NAC)
}

\author{
Pilar Almela, Javier Navarro-Zaragoza, Juan-Antonio García-Carmona, Lucía Mora, Juana Hidalgo, \\ María-Victoria Milanés, María-Luisa Laorden*
}

Departamento de Farmacología, Facultad de Medicina, Universidad de Murcia, Murcia, Spain

\begin{abstract}
Stress induces the release of the peptide corticotropin-releasing factor (CRF) into the ventral tegmental area (VTA), and also increases dopamine (DA) levels in brain regions receiving dense VTA input. Since the role of stress in drug addiction is well established, the present study examined the possible involvement of CRF1 receptor in the interaction between morphine withdrawal and catecholaminergic pathways in the reward system. The effects of naloxone-precipitated morphine withdrawal on signs of withdrawal, hypothalamo-pituitary-adrenocortical (HPA) axis activity, dopamine (DA) and noradrenaline (NA) turnover in the nucleus accumbens (NAC) and activation of VTA dopaminergic neurons, were investigated in rats pretreated with vehicle or CP-154,526 (selective CRF1R antagonist). CP-154,526 attenuated the increases in body weight loss and suppressed some of withdrawal signs. Pretreatment with CRF1 receptor antagonist resulted in no significant modification of the increased NA turnover at NAc or plasma corticosterone levels that were seen during morphine withdrawal. However, blockade of CRF1 receptor significantly reduced morphine withdrawal-induced increases in plasma adrenocorticotropin (ACTH) levels, DA turnover and TH phosphorylation at Ser40 in the NAc. In addition, CP-154,526 reduced the number of TH containing neurons expressing c-Fos in the VTA after naloxone-precipitated morphine withdrawal. Altogether, these results support the idea that VTA dopaminergic neurons are activated in response to naloxone-precipitated morphine withdrawal and suggest that CRF1 receptors are involved in the activation of dopaminergic pathways which project to NAc.
\end{abstract}

Citation: Almela P, Navarro-Zaragoza J, García-Carmona J-A, Mora L, Hidalgo J, et al. (2012) Role of Corticotropin-Releasing Factor (CRF) Receptor-1 on the Catecholaminergic Response to Morphine Withdrawal in the Nucleus Accumbens (NAC). PLoS ONE 7(10): e47089. doi:10.1371/journal.pone.0047089

Editor: Gilberto Fisone, Karolinska Inst, Sweden

Received May 14, 2012; Accepted September 10, 2012; Published October 10, 2012

Copyright: (c) 2012 Almela et al. This is an open-access article distributed under the terms of the Creative Commons Attribution License, which permits unrestricted use, distribution, and reproduction in any medium, provided the original author and source are credited.

Funding: This work was supported by Ministerio de Ciencia e Innovación (SAF2010-17907), Red de Trastornos Adictivos (RTA; RD06/0001/1006) and Fundación Séneca (15405/PI/10), Región de Murcia. The funders had no role in study design, data collection and analysis, decision to publish, or preparation of the manuscript

Competing Interests: The authors have declared that no competing interests exist.

* E-mail: laorden@um.es

\section{Introduction}

Addiction research has traditionally focused on dopamine (DA) and positive reinforcement-based behaviours. However, increased focus has been placed on negative reinforcement as a key driver in the addiction process. Noradrenergic and corticotropin-releasing factor (CRF) signalling systems have been heavily implicated in negative reinforcement [1-3]. Both noradrenaline (NA) and CRF are critical in behavioural aspects of addiction, including the reinforcing properties of drugs $[4,5]$ and anxiogenic effects of drug withdrawal $[6,7]$. GRF is an important regulator of stress response that exerts its actions through activation of two different types of G-protein-coupled receptors: CRF1 (expressed throughout the entire central nervous system) and CRF2 (displays more restrictive expression that CRF1) [8]. CRF1 binding sites have been demonstrated in several key brain areas involved in the addictive processes [e.g., cerebral cortex, hippocampus, hypothalamus, amygdala, nucleus of tractus solitarius (NTS), ventral tegmental area (VTA) and nucleus accumbens (NAc) that are involved in reward, reinforcement, craving and aversive effects of drugs of abuse [9]. Moreover, the decreased brain reward function associated with drug withdrawal is CRF1 receptor-dependent [10].

Enhanced responsiveness of hypothalamo-pituitary-adrenocortical (HPA) axis after morphine withdrawal, which results in an increase in CRF transcription and boost of adrenocorticotropin and corticosterone secretion, has been associated with activation of noradrenergic neurons in the NTS that project to the hypothalamic paraventricular nucleus (PVN) $[11,12]$. CRF is also located outside the HPA axis to control autonomic and behavioural responses to stressors. NA would modulate the release of CRF in the brain stress system, including the central amygdala, the bed nucleus of stria terminalis and the PVN of the hypothalamus. CRF from these nuclei would induce the release of NA by the brain stem noradrenergic areas $[13,14]$. In addition, the NAc and its dopaminergic inputs from the VTA is one of the most important anatomical substrates for drug reward and aversion [15,16]. Muopioid receptor agonists increase DA release in terminal regions in the NAc by inhibiting GABAergic neurons in the VTA, which provide tonic inhibition of DA neurons [17]. Research indicates that midbrain DA neurons not only show a pattern signaling the magnitude, delay and probability of rewards $[18,19]$ but also code 
negative motivation and aversive events [20]. Stress can induce relapse in addicted or abstinent humans [21] and reinstate drug seeking in animal models of relapse [22]. Since stress not only increases DA release in brain regions receiving dense VTA input [23-26] but also stimulates the release of CRF into the VTA [27], it has been suggested that GRF may directly excite the midbrain DA system [28].

Altogether, these results suggest the existence of a DA/NA-CRF loop; however, the possible involvement of CRF receptor subtypes in the interaction between morphine withdrawal and catecholaminergic pathways in the reward system is not well documented. Therefore, here we examined: 1) the role of CRF1 receptor in mediating somatic and behavioural states produced during withdrawal from morphine dependence, 2) the activation of HPA axis induced by morphine withdrawal in morphine dependent rats pretreated with a CP-154,526, a selective CRF1 receptor antagonists, 3) the response of dopaminergic and noradrenergic pathways innervating the NAc and the effects of CRF1 receptor blockade on tyrosine hydroxylase $(\mathrm{TH})$ phosphorylation in Serine (Ser)40 and Ser31 in the NAc and 4) the effects of CRF1 receptor blockade on activation of VTA dopaminergic neurons during morphine withdrawal, as reflected by c-Fos expression.

\section{Results}

In accordance with previous findings, Student's t-test showed that rats receiving long-term morphine treatment had significantly lower body weight gain (Fig. 1A) which might be due to the reduced food intake observed during morphine treatment [29].
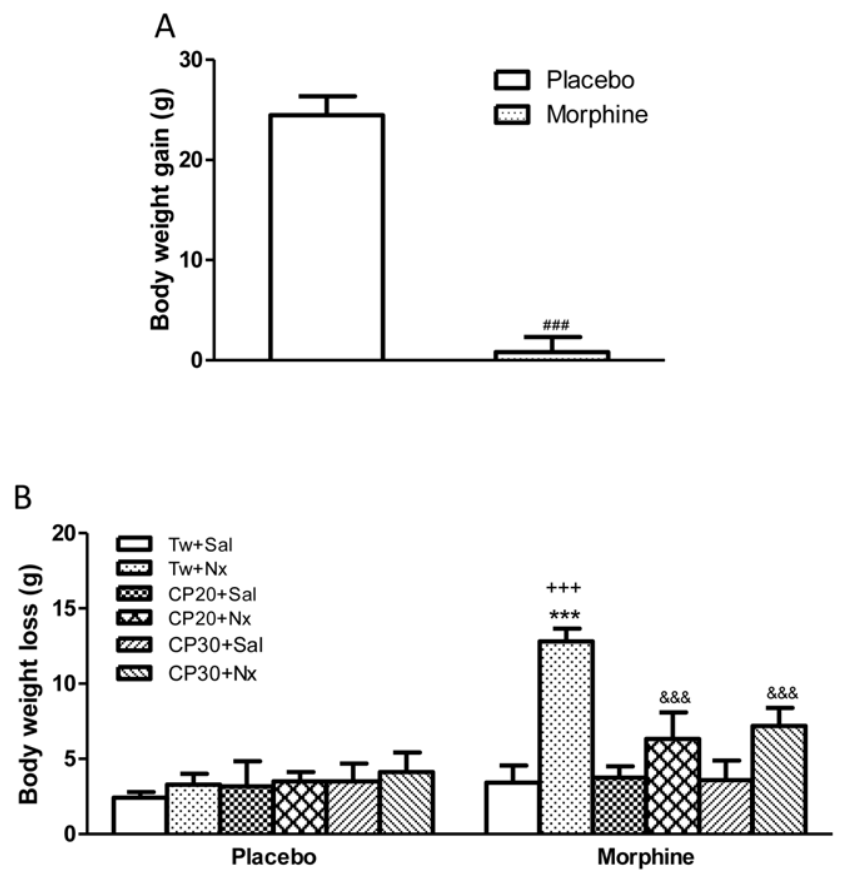

Figure 1. (A) Body weight gain after s.c. implantation of placebo or morphine (75 $\mathbf{~ m g )}$ pellets. (B) Rats were injected with Tween 80 (Tw) or CP-154,526 (20 or $30 \mathrm{mg} / \mathrm{kg}$, i.p., CP) 30 min before saline (Sal) or naloxone (1 mg/kg, s.c., $\mathrm{Nx}$ ) to evaluate body weight loss. Data are the mean \pm SEM $(n=5-28)$. \#\#\#p $<0.001$ versus placebo; ${ }^{* * *} p<0.001$ versus morphine+Tw+Sal; +++ $p<0.001$ versus place-

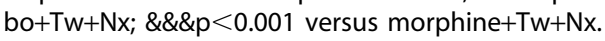
doi:10.1371/journal.pone.0047089.g001
Effects of CRF1 receptor antagonist on naloxoneprecipitated withdrawal signs in morphine dependent rats

Two-way ANOVA showed that there was a significant morphine pretreatment main effects $[\mathrm{F}(1,63)=20.49$, $\mathrm{p}<0.0001]$, a significant naloxone main effect $[\mathrm{F}(5,63)=6.09$, $\mathrm{p}=0.0001]$ and a significant interaction between chronic pretreatment $\mathrm{x}$ acute treatment $[\mathrm{F}(5,63)=5.09, \mathrm{p}=0.0006]$. Newman Keuls' post hoc test showed that naloxone injection to morphine dependent rats pretreated with vehicle produced a significant $(p<0.001)$ increase in body weight loss compared with the control pellet-treated group also receiving naloxone and with morphine treated rats given saline (Fig. 1B). However, administration of naloxone to control rats resulted in no significant changes in body weight loss $1 \mathrm{~h}$ after drug injection compared with control rats receiving saline. A significant decrease $(p<0.001)$ in body weight loss was seen in morphine withdrawn rats pretreated with the CRF1 receptor antagonist CP-154,526 (20, $30 \mathrm{mg} / \mathrm{kg}$ i.p.) compared with morphine withdrawn rats receiving vehicle instead of CP-154,526.

Naloxone-precipitated withdrawal also caused characteristic signs of abnormal behaviour, such as ptosis, teeth-chattering, tremor, piloerection, lacrimation, rinorrhea, spontaneous jumping, wet-dog shakes, salivation and diarrhoea. A significant lower frequency or total suppression of four of the ten signs (rinorrhea, spontaneous jumping, salivation and diarrhoea) was noted in morphine dependent rats pretreated with CP-154,526 (20 or $30 \mathrm{mg} / \mathrm{kg}$ i.p.) before naloxone (Table 1).

\section{Effects of CRF1 receptor blockade on morphine withdrawal-induced HPA axis activation}

We measured plasma ACTH and corticosterone concentrations (as HPA axis activation markers) in blood samples obtained from morphine dependent or control rats $60 \mathrm{~min}$ after injection of saline or naloxone. Two-way ANOVA indicated that there was a significant morphine pretreatment main effects [ACTH:

Table 1. Behavioural profiles after morphine withdrawal precipitated by naloxone $(\mathrm{nx})$ in animals chronically administered with vehicle (tween80) or CP-154,526 (CP).

\begin{tabular}{lll}
\hline Withdrawal signs & Vehicle+nx & CP20+nx CP30+nx \\
\hline Ptosis & $2 / 7$ & $0 / 50 / 5$ \\
Teeth-chatering & $7 / 7$ & $2 / 53 / 5$ \\
Tremor & $3 / 7$ & $2 / 52 / 5$ \\
Piloerection & $0 / 7$ & $0 / 50 / 5$ \\
Lacrimation & $2 / 7$ & $0 / 51 / 5$ \\
Rinorrhea & $6 / 7$ & $0 / 5^{*} 0 / 5^{*}$ \\
Spontaneous jumping & $6 / 7$ & $0 / 5^{*} 0 / 5^{*}$ \\
Wet-dog shakes & $4 / 7$ & $3 / 53 / 5$ \\
Salivation & $7 / 7$ & $0 / 5^{* *} 0 / 5^{* *}$ \\
Diarrhoea & $5 / 7$ & $0 / 5^{*} 0 / 5^{*}$ \\
\hline
\end{tabular}

${ }^{*} p<0.05$,

** $p<0.01$ versus vehicle $+n x$ ( $X^{2}$ test). Animals received subcutaneous implantation of morphine $(75 \mathrm{mg})$ pellets. On day 6 rats were injected with vehicle or CP-154,526 (20 or $30 \mathrm{mg} / \mathrm{kg}$, i.p.) $30 \mathrm{~min}$ before naloxone $(1 \mathrm{mg} / \mathrm{kg}$, s.c.) and were decapitated $60 \mathrm{~min}$ after the opioid antagonist administration. The behaviours are shown as the number of animals exhibiting the withdrawal signs of the total number of animals observed for $60 \mathrm{~min}$.

doi:10.1371/journal.pone.0047089.t001 
$F(1,52)=9.59, \quad p=0.0031 ; \quad$ corticosterone: $\quad F(1,47)=52.56$, $\mathrm{p}<0.0001)$ ], significant acute treatment [ACTH: $\mathrm{F}(3,52)=5.71$, $p=0.0019$; corticosterone: $F(3,47)=16.53 p<0.0001)]$, a significant interaction between chronic pretreatment and acute treatment, [ACTH: $\quad \mathrm{F}(3,52)=5.69, \quad \mathrm{p}=0.0019$; corticosterone: $\mathrm{F}(3,47)=23.88, \mathrm{p}<0.0001)]$. As shown in Fig. $2 \mathrm{~A}$ and $\mathrm{B}$, naloxone-precipitated morphine withdrawal evoked a dramatic increase of both ACTH and corticosterone secretion $(\mathrm{p}<0.001)$. To evaluate whether a causal link exists between CRF1 receptor activation and HPA axis hyperactivation during morphine withdrawal, we measured plasma ACTH and corticosterone concentrations in animals made dependent on morphine and pretreated with $\mathrm{CP}-154,526$ (20 $\mathrm{mg} / \mathrm{kg}$, i.p.) $30 \mathrm{~min}$ before naloxone administration. CP-154,526 significantly $(p<0.001)$ reduced morphine withdrawal-induced increases in plasma ACTH compared with rats receiving vehicle instead of CP-154,526, whereas plasma ACTH levels in morphine-treated rats given saline or placebo-treated rats receiving saline or naloxone were not modified by CP-154,526. However, naloxone-precipitated morphine withdrawal produced a significant $(\mathrm{p}<0.001)$ increase in corticosterone levels in animals receiving CP-154,526 compared with morphine-treated rats receiving CP-154,526+saline and placebo rats treated with the CRF1 receptor antagonist+naloxone.

A

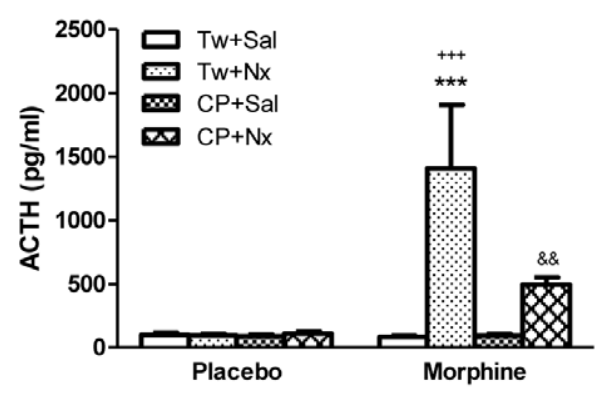

B

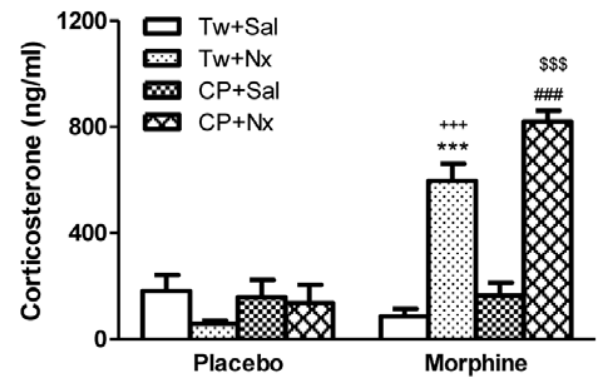

Figure 2. Plasma adrenocorticotropic hormone (ACTH) (A) and corticosterone (B) concentrations $60 \mathrm{~min}$ after saline (Sal) or naloxone ( $\mathrm{Nx}$ ) administration to placebo or morphine dependent rats pretreated with Tween 80 (Tw) or CP-154,526 (20 mg/ kg, i.p., CP). Data are the mean \pm SEM $(n=6-9) .{ }^{* * *} p<0.001$ versus the morphine dependent group receiving saline instead of naloxone; $+++p<0.001$ versus the placebo group injected with $\mathrm{Tw}+\mathrm{Nx} ; \& \& \mathrm{p}<0.01$

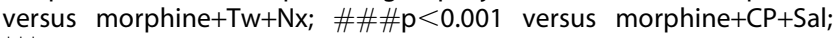
$\$ \$ p<0.001$ versus placebo+CP+Nx.

doi:10.1371/journal.pone.0047089.g002
Effects of CRF1 receptor antagonist on naloxone-induced DA and NA turnover and TH phosphorylation in the NAC

Analysis of DOPAC/DA and NMN/NA ratio revealed a chronic drug effect [DOPAC/DA: $\mathrm{F}(1,48)=14.10, \mathrm{p}=0.0005$; MHPG/NA: $\mathrm{F}(1,48)=80.44, \mathrm{p}<0.0001]$, an opioid withdrawal effect [DOPAC/DA: $\mathrm{F}(5,48)=4.41, \mathrm{p}=0.0022 ; \mathrm{MHPG} / \mathrm{NA}$ : $\mathrm{F}(5,48)=16.07, \mathrm{p}<0.0001]$ and a chronic drug treatment $\mathrm{x}$ opioid withdrawal [DOPAC/DA: $\mathrm{F}(5,48)=3.80, \mathrm{p}=0.0056$; MHPG/ NA: $F(5,48)=14.80, p<0.0001]$. Post hoc test revealed that $60 \mathrm{~min}$ after naloxone administration to morphine dependent rats there was an increase $(\mathrm{p}<0.001)$ in the DOPAC/DA and MHPG/ NA ratio (as index of NA turnover) when compared with morphine dependent rats receiving saline instead of naloxone or naive rats injected with naloxone (Fig. 3A,B). However, administration of naloxone to placebo-pelleted rats resulted in no significant changes in DA and NA turnover $60 \mathrm{~min}$ after drug injection compared with control rats receiving saline. As shown in Fig. 3A, the administration of CP-154,526 (20 or $30 \mathrm{mg} / \mathrm{kg}$ ) significantly $(p<0.01)$ decreased DOPAC/DA ratio versus morphine withdrawn rats receiving vehicle instead of CP-154,526. No alterations in NA turnover in the NAc were found after naloxoneprecipitated morphine withdrawal in rats pretreated with CP154,526 (Fig. 3B).

In the present work we also examined $\mathrm{TH}$ phosphorylation at Ser31 and Ser40. Two-way ANOVA performed on $\mathrm{TH}$ phosphorylation at Ser31 indicated that there was a not significant morphine pretreatment main effect, no significant naloxone main effect nor a significant interaction. However, two-way ANOVA results for $\mathrm{TH}$ phosphorylated at Ser40 revealed a significant effects of morphine chronic pretreatment $[\mathrm{F}(1,40)=22.22$,
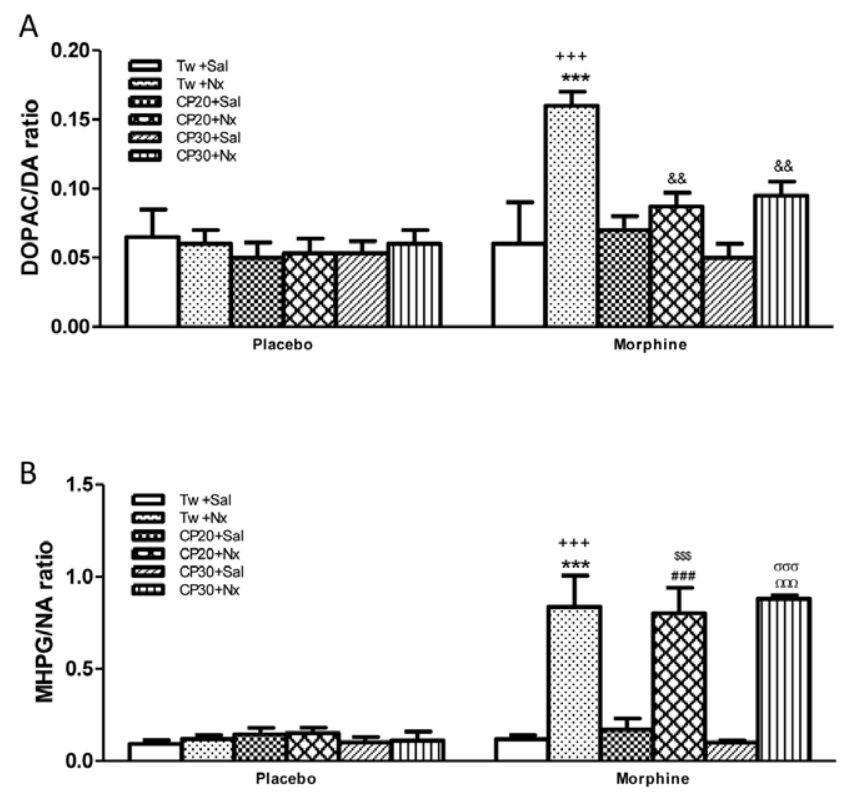

Figure 3. DOPAC/DA (A) and MHPG/NA (B) ratio in the nucleus accumbens (NAC) 60 min after saline (Sal) or naloxone (Nx) administration to placebo or morphine dependent rats pretreated with Tween 80 (Tw) or CP-154,526 (20 or 30 mg/kg, i.p., CP) $(\mathbf{A}, \mathbf{B}, \mathbf{C}$,$) . Data are the mean \pm \operatorname{SEM}(n=5) .{ }^{* * *} p<0.001$, versus the morphine dependent group receiving saline instead of naloxone; $+++p<0.001$ versus the placebo group injected with $\mathrm{Tw}+\mathrm{Nx} ; \& \& p<0.01$

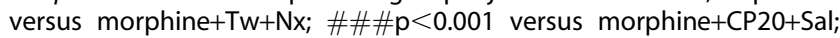
$\$ \$ \mathrm{p}<0.001$ versus placebo+CP20+Nx; $\Omega \Omega \Omega \mathrm{p}<0.001$ versus morphine+CP30+Sal; $\sigma \sigma \sigma p<0.001$ versus placebo+CP30+Nx. doi:10.1371/journal.pone.0047089.g003 
$\mathrm{p}<0.0001]$, acute treatment $[\mathrm{F}(3,40)=12, \mathrm{p}<0.0001]$ and $\mathrm{a}$ significant interaction between chronic pretreatment and acute treatment $[\mathrm{F}(3,40)=11.80, \mathrm{p}<0.0001]$. As shown in Fig. $4 \mathrm{~A}, \mathrm{TH}$ phosphorylated at Ser31 was unchanged in morphine dependent rats treated with vehicle+naloxone or CP-154,526+naloxone. However, we observed an significant $(\mathrm{p}<0.01)$ enhancement in the immunoreactivity corresponding to $\mathrm{TH}$ phosphorylated at Ser40 in the NAc from morphine dependent rats injected with naloxone (Fig. 4B) versus morphine dependent rats receiving saline instead of naloxone or placebo groups injected with naloxone. Pretreatment with CP-154,526 (20 mg/kg i.p.) significantly $(\mathrm{p}<0.001)$ modified the increase in the number of $\mathrm{TH}$ cells phosphorylated at Ser40 after naloxone-precipitated morphine withdrawal that was seen in NAc (Fig. 4B).

\section{Induction of c-Fos in total TH positive neurons in the VTA}

c-Fos protein, the product of c-fos immediate early gene, has been used as a marker for neuronal activation (Fig. 5 A, B, G). Two-way ANOVA for c-Fos expression revealed a main effect of morphine pretreatment $[\mathrm{F}(1,15)=27.05, \mathrm{p}=0.0001]$ acute treatment $[\mathrm{F}(1,15)=34.23, \mathrm{p}<0.0001]$ and a significant interaction between chronic pretreatment and acute treatment $[\mathrm{F}(1,15)=$ $7.19, \mathrm{p}=0.0171]$. Post hoc test showed that there was a significant increase $(p<0.001)$ in the number of $c-F o s$ positive neurons after naloxone-precipitated morphine withdrawal when compared with the control group receiving naloxone (Fig. 5G). Two-way ANOVA showed that acute treatment $[\mathrm{F}(1,15)=12.06, \mathrm{p}=0.0034]$ had a significant effect on the number of TH positive neurons. NewmanKeuls post hoc test shows that there was a significant $(\mathrm{p}<0.05)$ lower number of $\mathrm{TH}$ positive neurons in morphine withdrawal rats treated with CP-154,526 versus the group treated with vehicle instead of CRF1 receptor antagonist (Fig. $5 \mathrm{H}$ ). To reveal if TH neurons are activated during naloxone-precipitated morphine withdrawal, c-Fos and TH immunostaining was co-localized and quantified in sections of the VTA. Two-way ANOVA revealed main effect of morphine pretreatment $[\mathrm{F}(1,15)=29.05, \mathrm{p}<0.0001]$ and acute treatment $[\mathrm{F}(1,15)=31.06, \mathrm{p}<0.0001]$. Post hoc comparisons showed a significant $(\mathrm{p}<0.001)$ increase in the number of TH-containing neurons expressing c-Fos after naloxone administration to morphine dependent rats (Fig. 5C, E, I). Pretreatment with CP-154,526 (20 mg/kg, i.p.) significantly $(p<0.001)$ decreased the number of $\mathrm{c}$-Fos positive cells and the number of $\mathrm{TH}$ containing neurons expressing c-Fos observed in morphine withdrawn rats treated with vehicle (Fig. 5C,D, E, F,I). In addition, the CRF1 receptor antagonist decreases the number of TH immunoreactivity neurons in the NAc (Fig. $5 \mathrm{H}$ ).

\section{Discussion}

Adaptive changes have been reported in a variety of signalling pathways and gene expression after acute and chronic morphine exposure, and during morphine withdrawal. However, it is during withdrawal syndrome when several of these adaptive changes become evident. In this regard, present data demonstrated that chronic morphine treatment did not change HPA axis activity, DA and NA turnover, TH phosphorylation and c-Fos expression. In contrast, these parameters were modified following naloxoneprecipitated withdrawal.

Several studies have previously shown that increased CRF release contributes to the anxiety and aversive states produced by drug withdrawal [30,31] and recruitment of the CRF system has been hypothesized to be involved in drug dependence [1]. Accordingly, antagonism of CRF neurotransmission attenuated the anxiety-like and aversive effects of drug withdrawal [14]. Consistent with these studies, we observed that CP-154,526 suppressed four behavior signs (rinorrhea, spontaneous jumping, salivation and diarrhoea). In agreement with present results, genetic disruption of CRF1 receptor pathways as well as pharmacological antagonism of the CRF1 receptor eliminates the negative affective states of opioid withdrawal [32,33]. In addition, previous [33] and present results demonstrate that CP154,526 attenuated the weight loss and others somatic signs of morphine withdrawal. In contrast, it has been showed that CRF1 receptor-deficient mice display increased somatic reactions to
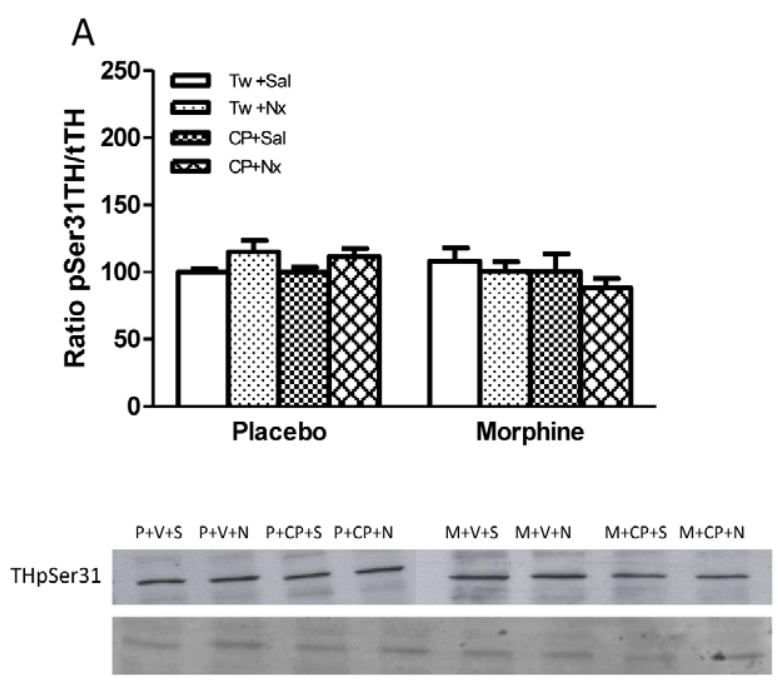

B
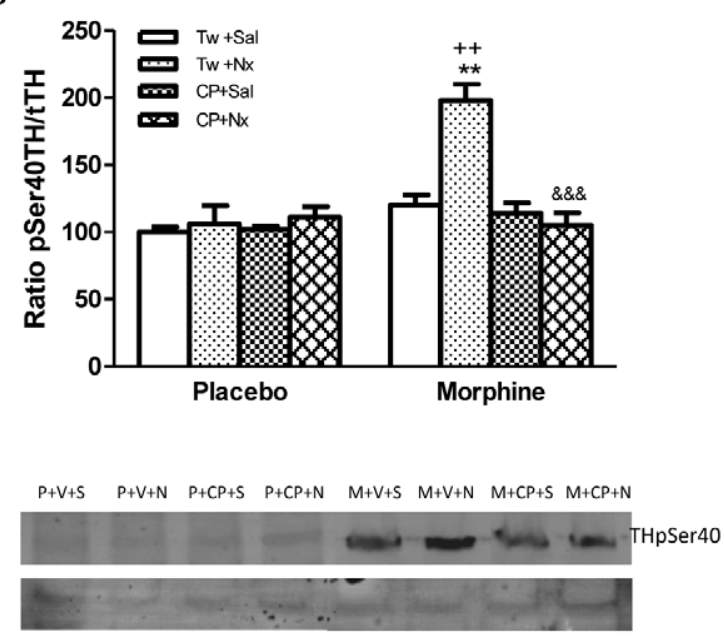

Figure 4. Western-blotting analysis of TH phosphorylated (p) at Ser 31 (A) or Ser40 (B)/total (t)TH ratio in the nucleus accumbens (NAc) 60 min after saline (Sal, S) or naloxone (Nx, N) administration to placebo (P) or morphine (M) dependent rats pretreated with Tween 80 (Tw, V) or CP-154,526 (20 mg/kg, i.p., CP) (A, B). The immunoreactivity corresponding to TH phospho-Ser31 or TH phospho-Ser40 is expressed as a percentage of that in the control group defined as $100 \%$ value. Data are the mean $\pm \operatorname{SEM}(n=6)$. ${ }^{* *} p<0.01$, versus the morphine dependent group receiving saline instead of naloxone; $++p<0.01$ versus the placebo group injected with $\mathrm{Tw}+\mathrm{Nx} ; \& \& \& p<0.001$ versus morphine $+\mathrm{Tw}+\mathrm{Nx}$.

doi:10.1371/journal.pone.0047089.g004 
$\mathbf{P}+\mathbf{T w}+\mathbf{N x}$

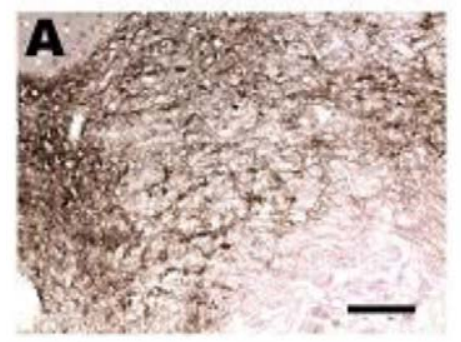

$\mathbf{M}+\mathbf{T w}+\mathbf{N x}$

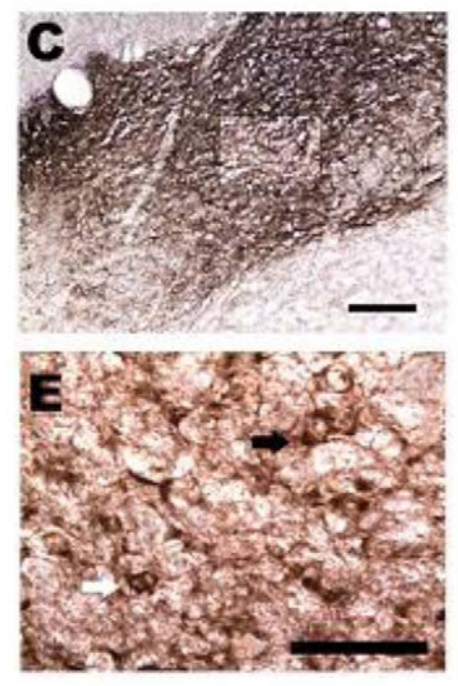

$\mathbf{P}+\mathbf{C P}+\mathbf{N x}$

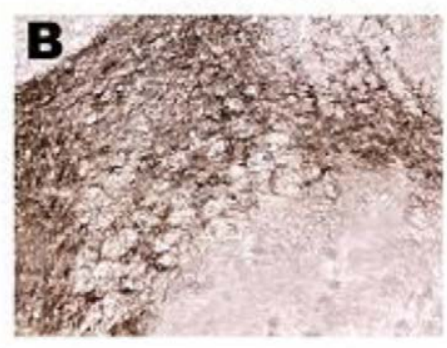

$\mathbf{M}+\mathbf{C P}+\mathbf{N x}$

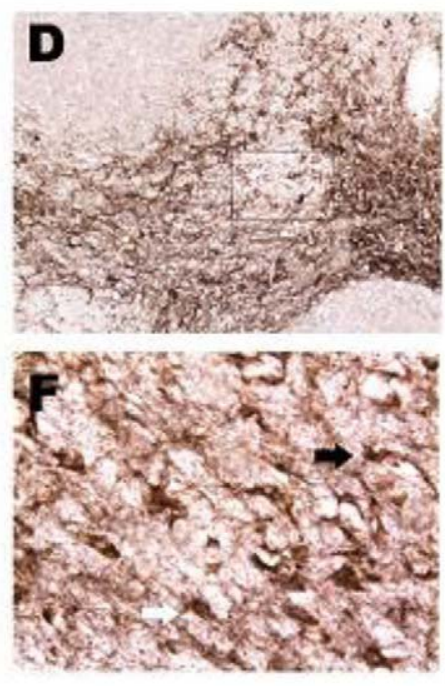

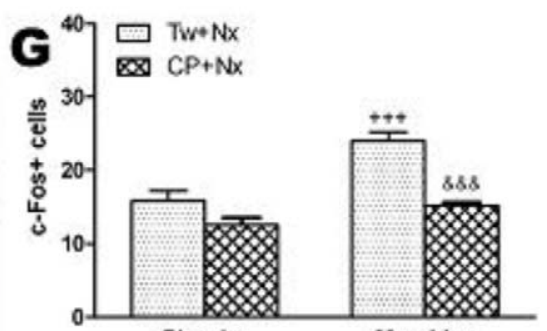

Placebo

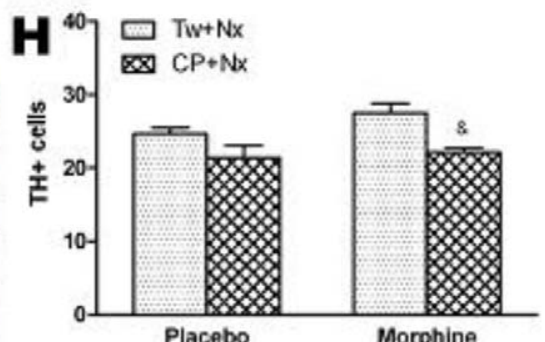

Placebo

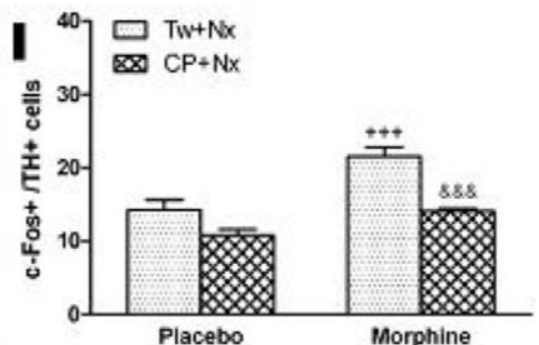

Figure 5. Photographs $(A, B, C, D, E, F)$ represent TH positive neurons coexpressing C-Fos in the ventral tegmental area (VTA) 60 min after naloxone $(\mathrm{Nx}, \mathrm{N})$ administration to placebo $(\mathrm{P})$ or morphine $(\mathrm{M})$ dependent rats pretreated with Tween 80 (Tw) or CP-154,526 (20 mg/kg, i.p., CP). Black arrows: c-Fos+/TH+ neurons; white arrows: c-Fos-/TH+ neurons (E,F). Quantitative analysis of the number c-Fos+, TH+ or $c$-Fos $+/ \mathrm{TH}+$ neurons $(\mathrm{G}, \mathrm{H}, \mathrm{I})$. Data are expressed as the mean $\pm \mathrm{SEM}(\mathrm{n}=6-7) .+++p<0.001$ versus the placebo group injected with $\mathrm{Tw}+\mathrm{Nx} ; \& \mathrm{p}<0.05$, $\& \& \& p<0.001$ versus morphine+Tw+Nx.

doi:10.1371/journal.pone.0047089.g005

opiate withdrawal indicating a clear-cut dissociation between affective-like and somatic signs [34]. These opposite results could be explained by the different protocols used: CRF1 receptordeficient mice versus rats pretreated with a selective CRF1 receptor antagonist.

According to previous reports, present findings demonstrated that naloxone administration to morphine dependent rats significantly elevated plasma ACTH and corticosterone concentrations. Enhanced responsiveness of the HPA axis after morphine withdrawal has been associated with activation of noradrenergic neurons in the NTS that project to the hypothalamic PVN, suggesting that one of the neuronal mechanisms that underlie morphine withdrawal-induced activation of the HPA axis may be dependent on activation of noradrenergic pathways innervating the PVN $[35,11,12,36]$. Our results show that pretreatment with CP-154256 did not block the corticosterone release that is produced as a consequence of morphine withdrawal. However, ACTH concentrations were found to be decreased in animals pretreated with CP-154,526. The relationship between HPA activity and drug withdrawal-induced behaviour alterations and changes in the brain stress system has not been elucidated, and contradictory results have been shown. CRF1 receptor has been shown to play a major role mediating the effects of CRF on behavioural responses to lorazepam withdrawal but not some of the neuroendocrine effects. Thus according to present results, the CRF1 receptor antagonist R121919 attenuated the behavioural and autonomic signs of lorazepam withdrawal and ACTH secretion, whereas corticosterone levels were not altered [37]. Furthermore in clinical studies CRF1 receptor antagonists produced anxiolytic-like effects in depressed patients in the absence of effects on CRF-stimulated HPA axis activity [38]. A potential explanation to present findings is that, although CRF is thought to be a major secretagogue in stimulating ACTH secretion, arginine vasopressin (AVP), catecholamines, and other factors also play a role [39]. In addition, there is increasing evidence that AVP and CRF production and release from the parvocellular PVN neurons are under independent regulation. Thus, it is possible that AVP may play an important role in mediating the pituitary-adrenal response to drug withdrawal and stress [40].

DA signalling in the NAc is involved in the integration of sensory information and the initiation of the subsequent behavioural responses to diverse stimuli [41]. The perception and behavioural consequences of rewarding and aversive substrates mediating these opposing phenomena are unclear. According to the reward coding hypothesis [42-45], mesolimbic DA neurons are inhibited or unresponsive to aversive stimuli, and increased DA release only occurs with reward-related stimuli. However, 
electrophysiological studies clearly demonstrate that the activity of a subset of DA neurons in the VTA and substantia nigra can increase in response to aversive stimuli $[46,20,47,48]$. Our data clearly demonstrate that naloxone-precipitated morphine withdrawal increases the activity of VTA TH-positive neurons (as reflected by c-Fos expression) concomitantly with an enhancement of DA turnover in the NAc, which receives projections from VTA, in parallel to increased $\mathrm{TH}$ phosphorylation (activation) at Ser40. According to these data, a previous study has demonstrated that dorsal striatum and NAc core are neural substrates, which are involved in the perception of aversive stimuli suggesting that DA response in these regions can be triggered by aversive states in the same fashion as rewarding stimuli [49].

While our data suggest that DA neurons in the VTA exhibit significant activation in response to an aversive stimulus that produce a proportional response in DA turnover and $\mathrm{TH}$ activation in the terminal region, others have reported that opioid withdrawal is associated with decreased activity of dopaminergic neurons and decreased DA output to the NAc $[50,51,52]$. Several factors may account for the contrasting results in the reward pathways, including different methods (microdialysis or electrophysiological studies versus HPLC or immunohistochemistry), withdrawal conditioned to the discontinuation of treatment or different doses of naloxone used by different groups.

On the other hand, direct noradrenergic inputs from the NTS to the NAc have been described [53]. The present findings demonstrated that naloxone administration to morphine dependent rats significantly elevated NA turnover in the NAc, which receives projections from NTS. Previous reports have shown that naloxone-precipitated morphine withdrawal increases the activity of NTS TH-positive neurons [12,54]. Together, all these data implicated NA neurons in NTS in the aversiveness of acute opioid withdrawal. Support for this idea can be found in a number of studies that implicate the NTS-A2 noradrenergic cells group in that affective disorder associated with drug withdrawal $[6,54-56]$. Changes in the state of phosphorylation of $\mathrm{TH}$, the rate limiting enzyme in the synthesis of catecholamines, are critically involved in the regulation of catecholamines, synthesis and function. In particular, increases in the phosphorylation of Ser40 and Ser31 accelerate TH activity, thereby simulating production of neurotransmitter in catecholamines terminals [57]. Using phosphorylation state-specific antibodies directed toward Ser40 or Ser31, in the present study we have shown that naloxone-precipitated withdrawal greatly increased the level of $\mathrm{TH}$ phosphorylation at Ser40, without changes at Ser31, in NAc. Together, these data suggest that Ser40 phosphorylation of $\mathrm{TH}$ may be an important modulator of $\mathrm{TH}$ activity and might be directly involved with regulating NA and DA turnover in the NAc from morphine withdrawn rats. Short-term regulation of catecholamines biosynthesis occurs through phosphorylation of $\mathrm{TH}$, which enhances enzymatic activity [58].

On the other hand, pretreatment with the selective CRF1 receptor antagonist CP-154,526 did not block the increased NA turnover in the NAc during morphine withdrawal suggesting that the activation of the CRF1 receptor subtype is not responsible for the elevation of NA neurotransmission innervating the NAc. Our results are consistent with findings from our laboratory demonstrating that CRF1 receptor is not implicated in the enhancement of NA turnover in the PVN, which receives projections from NTS, observed during morphine withdrawal [33]. In addition, a previous study using CRF1receptor-deficient mice demonstrated that GRF1 receptor is not responsible for the phosphorylation of TH observed in NTS after naloxone-precipitated withdrawal in wild-type mice [56].
On the other hand, we observed that the CRF1 receptor antagonist CP-154,526 decreased DA turnover in the NAc from morphine withdrawn rats in parallel with a decrease in the phosphorylation of TH at Ser40 in the NAc. According to these data, prior studies have shown that CRF1 receptor activation can increase DA cell firing and DA release in brain structures associated with reward, including the VTA and NAc [25,58]. Since association of Ser40 phosphorylation with TH activity and catecholamine synthesis in vivo has been shown [59] present results indicate that CRF1 receptor is involved in TH phosphorylation observed in the NAc after naloxone-precipitated morphine withdrawal and suggest that $\mathrm{TH}$ activation is responsible for the enhancement of DA turnover.

Using dual immunolabeling for c-Fos (a marker of neuronal activity) and $\mathrm{TH}$, present data show that $\mathrm{TH}$ positive neurons in the VTA coexpress c-Fos in morphine withdrawn rats. Present results show a decrease in the number of c-Fos positive cells and in TH positive neurons coexpressing c-Fos in the VTA from morphine withdrawn rats treated with CP-154,526. Altogether, these results support the idea that VTA dopaminergic neurons are activated in response to aversive stimulus and suggest that CRF1 receptors are involved in the activation of dopaminergic pathways which project to NAc.

Our data clearly demonstrated that naloxone-precipitated morphine withdrawal activated VTA dopaminegic neurons and also increased DA turnover in the NAc, which receives dense VTA input. Since DA responses in these anatomical structures can be triggered by aversive states in the same fashion as rewarding stimuli, our findings suggest the existence of some overlap in the neurochemistry of withdrawal and pleasure processing in the mesolimbic pathway. In addition, we showed that CRF1 receptor antagonist suppressed or attenuated some signs of morphine withdrawal, ACTH hypersecretion, DA turnover and TH phosphorylation in the NAc, in parallel with a decrease in the number of TH containing neurons expressing c-Fos in the VTA. Electrophysiological studies demonstrated that application of CRF increased VTA DA neuronal firing in a concentration dependent manner. However, the precise mechanism of CRF regulation of dopaminergic cells in the VTA is also unclear and has been reported to involve CRF1 receptor-mediated activation of protein kinase $\mathrm{C}$ (PKC) [28] and possibly protein kinase A (PKA) [60] signaling and/or CRF2 receptor facilitation of NMDA receptor function [61]. In addition, experiments using CRF agonists, CRF antagonists and CRF-receptor deficient mice all led to the same conclusion that CRF increased VTA DA neurons through CRF1 receptor activation [28]. According to these data, present results suggest that GRF could activate the mesolimbic DA system after morphine withdrawal via CRF1 receptor activation. This study identifies a link between DA and CRF, which together have been implicated in drug abuse and support a role for CRF1 receptors like a potential therapeutic target to treat this disorder.

\section{Materials and Methods}

\section{Animals}

Male Sprague-Dawley rats (220-240 g at the beginning of the experiments) were housed four-to-five per cage under a 12-h light/ dark cycle (light: 8:00-20:00 h) in a room with controlled temperature $\left(22 \pm 2^{\circ} \mathrm{C}\right)$, humidity $(50 \pm 10 \%)$, food and water available ad libitum and prehandled for several days preceding the experiment to minimize stress. All surgical and experimental procedures were performed in accordance with the European Communities Council Directive of November 24, 1986 (86/609/ EEG) and approved by the local committees for animal research 
(REGA ES300305440012), Murcia. The study was approved by the University of Murcia bioethics committee (RD 1201/2005) and Ministerio de Ciencia y Tecnología (SAF2010-17907), Spain.

\section{Drug treatment and experimental procedure}

Rats were made dependent on morphine by subcutaneous implantation of two 75-mg morphine pellets (provided by the Ministerio de Sanidad, Madrid, Spain). This procedure has been shown to produce consistent plasma morphine concentration beginning a few hours after the implantation of the pellets and a full withdrawal syndrome after short-term treatment with opioid antagonists [62]. Dependence on morphine is achieved $24 \mathrm{~h}$ after implantation of pellets and remains constant for 15 days [63]. Control rats received placebo pellets containing the excipient without morphine. Six days after the implantation of morphine or placebo pellets, precipitated morphine withdrawal was induced by injection of naloxone $(1 \mathrm{mg} / \mathrm{kg}, \mathrm{sc})$ or saline (controls) and the rats were observed for behavioural signs of withdrawal. The withdrawal symptoms (ptosis, teeth-chattering, tremor, piloerection, lacrimation, rinorrhea, spontaneous jumping, wet-dog shakes, salivation and diarrhoea) were observed after naloxone administration for a period of $30 \mathrm{~min}$. In addition, body weight loss was determined as the difference between the weight determined immediately before saline or naloxone injection and a second determination made $60 \mathrm{~min}$ later. These signs are reliable markers of opiate withdrawal in morphine dependent rats. Rats weight gain was checked during the treatment to ensure that morphine was liberated correctly from the pellets because it is known that chronic morphine treatment induces a decrease in body weight gain due to lower caloric intake [64].

To determine the role of CRF1 receptor in the changes observed during morphine withdrawal, rats were treated with CP154,526 [ $\mathcal{N}$-butyl- $\mathcal{N}$-ethyl-2,5-dimethyl-7-(2,4,6-trimethyl-phenyl)pyrrolo(3,2-e)pyrimidin-4-amine] (20 or $30 \mathrm{mg} / \mathrm{kg}$ i.p., $30 \mathrm{~min}$ before naloxone or saline injection). The doses of CP-154,526, a selective CRF1 receptor antagonist, were selected based in a previous study from our laboratory [33]. These doses were dissolved in $10 \%$ Tween 80 and given in a volume of $1 \mathrm{ml} / \mathrm{kg}$.

Sixty min after saline or naloxone injection, rats were decapitated. The brains were rapidly removed, fresh-frozen, and stored immediately at $-80^{\circ} \mathrm{C}$ until use for Western Blot analysis and NA and DA turnover measurements. One set of each treatment group was randomly assigned for plasma ACTH and corticosterone determination.

\section{Radioimmunoassay}

Plasma levels of corticosterone and ACTH were measured by commercially available kits for rats $\left({ }^{125} \mathrm{I}\right.$-corticosterone and ${ }^{125} \mathrm{I}$ ACTH radioimmunoassay; MP Biomedicals, Orangeburg, NY). The sensitivity of the assay was $7.7 \mathrm{ng} / \mathrm{ml}$ for corticosterone and $5.7 \mathrm{pg} / \mathrm{ml}$ for ACTH.

\section{Estimation of NA, DA and their metabolites 3-methoxy-4- hydroxyphenylethylen glicol (MHPG) and 3,4- dihydroxyphenylacetic acid (DOPAC)}

NA and its metabolite in the central nervous system MHPG, DA and its metabolite DOPAC were determined by highperformance liquid chromatography with electrochemical detection. Each tissue was weighed, placed in a dry cooled propylene vial and homogenized with a Polytron-type homogenizer in $1.5 \mathrm{~mL}$ perchloric acid $(0.1 \mathrm{M})$. The homogenates were then centrifuged $\left(8000 \mathrm{~g}, 4^{\circ} \mathrm{C}, 15 \mathrm{~min}\right)$, the supernatant layer was removed into a $1 \mathrm{~mL}$ syringe and filtered through a $0.45 \mathrm{~mm}$ filter
(Millipore, Bedford, MA, USA) and centrifuged $\left(6000 \mathrm{~g}, 4^{\circ} \mathrm{C}\right.$, $20 \mathrm{~min}$ ) again through Ultra free MC 0.2 (Millipore). From each sample, $10 \mathrm{~mL}$ was injected into a $5 \mathrm{~mm}$ C18 reverse phase column (Waters, Milford, MA, USA) through a Rheodyne syringeloading injector $200 \mu \mathrm{L}$ loop. Electrochemical detection was accomplished with a glass carbon electrode set at a potential of +0.65 with respect to the $\mathrm{Ag} / \mathrm{AgCl}$ reference electrode (Waters). The mobile phase consisted of a $95 \%(\mathrm{v} / \mathrm{v})$ mixture of water and methanol with sodium acetate $(50 \mathrm{mM})$, citric acid $(20 \mathrm{mM}), \mathrm{L}-$ octyl-sodium sulphonate $(3.75 \mathrm{mM})$, di-n-butylamine $(1 \mathrm{mM})$ and EDTA $(0.135 \mathrm{mM})$, adjusted to $\mathrm{pH} 4.3$. The flow rate was $0.9 \mathrm{~mL} / \mathrm{min}$, and chromatographic data were analysed with Millenium 2010 Chromatography Manager Equipment (Millipore). NA, MHPG, DA and DOPAC were simultaneously detected by the described high-performance liquid chromatography method and were quantified by reference to calibration curves run at the beginning and at the end of each series of assays. Linear relationships were observed between the amount of standard injected and the peak height measured. The content of NA, DA and their metabolites in the NAc was expressed as ng/g protein. The NA or DA turnover was determined as the NA or DA ratio, which was calculated as follows: NA ratio $=\mathrm{MHPG} / \mathrm{NA}, \mathrm{DA}$ ratio $=$ DOPAC $/ \mathrm{DA}$

\section{Western blot analysis}

Western blot analysis was performed for THpSer31, THpSer40 and total TH determination. Samples were placed in homogenization buffer [phosphate buffered saline, $2 \%$ sodium dodecylsulfate (SDS), protease inhibitors (Roche, Germany) and phosphatase inhibitors (Calbiochem, Germany)] and homogenized for $50 \mathrm{~s}$ prior to centrifugation at $6000 \mathrm{~g}$ for $20 \mathrm{~min}$ at $4^{\circ} \mathrm{C}$. Total protein concentrations were determined spectrophotometrically using the bicinchoninic acid method [65]. The optimum amount of protein to be loaded was determined in preliminary experiments by loading gels with increasing protein contents (25 to $100 \mu \mathrm{g}$ ) from samples of each experimental group. Equal amounts of protein (50 $\mu \mathrm{g}$ /lane) from each sample were loaded on a $10 \%$ SDSpolyacrylamide gel (SDS-PAGE), electrophoresed, and transferred onto a poly vinylidene difluoride (PVDF) membrane using a Mini Trans-Blot Electrophoresis Transfer Cell (Bio-Rad Lab., California, USA). Non-specific binding of antibodies was mitigated by incubating membranes in $1 \%$ bovine serum albumin (BSA) in tris buffer saline tween (TBST: $10 \mathrm{mM}$ Tris-HCl, pH 7.6, $150 \mathrm{mM}$ $\mathrm{NaCl}, 0.05 \%$ Tween 20 ). The blots were incubated overnight at $4^{\circ} \mathrm{C}$, with the following primary antibodies: polyclonal anti- $\mathrm{TH}$ phosphoSer31 (1:300 dilution; AB5423, Millipore, USA), or polyclonal anti-TH phosphoSer40 (1:500 dilution; AB5935, Millipore, USA) in TBST with BSA. After extensive washings with TBST, the membranes were incubated for $1 \mathrm{~h}$, at room temperature, with the peroxidase-labeled secondary antibody antirabbit sc-2004 (Santa Cruz, USA) at 1:2500 dilution. After washing, immunoreactivity was detected with an enhanced chemiluminescent/chemifluorescent western blot detection system (ECL Plus, GE Healthcare, UK) and visualised by a Typhoon 9410 variable mode Imager (GE Healthcare). Antibodies were stripped from the blots by incubation with stripping buffer (glycine $25 \mathrm{mM}$ and SDS $1 \%, \mathrm{pH} 2$ ), for $1 \mathrm{~h}$ at $37^{\circ} \mathrm{C}$. We used anti-total TH (1:1000 dilution; AB152, Millipore, USA) as our loading control for all the experiments. The ratio of TH phosphoSer31/ $\mathrm{TH}$, TH phosphoSer40/TH was plotted and analysed.

Quantification of immunoreactivity corresponding to $\mathrm{TH}$ phosphoSer31 (60 kDa), TH phosphoSer40 (60 kDa) and $\mathrm{TH}$ $(62 \mathrm{kDa})$ bands was carried out by densitometry (AlphaImager, Nucliber, Madrid). The optical density was normalized to the 
Day 1

\begin{tabular}{|c|c|c|c|}
\hline & 0 & 30 & $60 \mathrm{~min}$ \\
\hline$\uparrow$ & $\uparrow$ & $\uparrow$ & $\uparrow$ \\
\hline \multirow[t]{3}{*}{$\begin{array}{c}2 \text { pellets } \\
\text { implantation }\end{array}$} & $\begin{array}{l}\text { vehicle or } \\
\text { CP-154,526 }\end{array}$ & $\begin{array}{l}\text { saline or } \\
\text { naloxone }\end{array}$ & kill \\
\hline & & & \\
\hline & & \multicolumn{2}{|c|}{$\begin{array}{c}\text { withdrawal signs } \\
\text { evaluation }\end{array}$} \\
\hline
\end{tabular}

Figure 6. Experimental protocol. Six days after placebo or morphine pellets, rats were treated with CP or vehicle 30 min before saline or naloxone injection and $60 \mathrm{~min}$ after the injection, rats were decapitated or perfused transcardiacally for biochemical assays (as described under Material and Methods).

doi:10.1371/journal.pone.0047089.g006

background values. Relative variations between bands of experimental samples and control samples were calculated in the same image.

\section{Immunohistochemistry. Double-labelling immunohistochemistry of c-Fos and TH-positive neurons in the VTA}

Animals were perfused transcardiacally, and brains were processed for visualization of c-Fos and $\mathrm{TH}$ by using previously published techniques [66]. For c-Fos/TH double-label immunohistochemistry, brain stem tissue sections from each rat in each treatment group were processed as follows: c-Fos was revealed with 3,3'-diaminobenzidine (DAB) (Sigma Chemical, Madrid, Spain) intensified with nickel in the first position, and $\mathrm{TH}$ was revealed with DAB in the second position. Different group sections were incubated in primary polyclonal anti-total TH (1:6000 dilution; $\mathrm{AB} 152)$, polyclonal anti-(c-Fos) antibody $(1: 10,000$ dilution; non-cross-reactive with Fos-B, Fra-1 or Fra-2; sc-52; Santa Cruz) and a secondary anti-rabbit IgG (diluted 1:500; Vector Laboratories) and c-Fos antibody-peroxidase complex was visualized by using a mixture of $\mathrm{NiSO}_{4} \cdot 6 \mathrm{H}_{2} \mathrm{O}(33.2 \mathrm{mg} / \mathrm{ml}), \mathrm{DAB}$ $(0.033 \%)$, and $0,014 \% \mathrm{H}_{2} \mathrm{O}_{2}$ in $0,175 \mathrm{M}$ sodium acetate solution $(\mathrm{pH} 7.5)$. Tissue sections were transferred into Milli-Q water (Millipore Corporation) to stop the color reaction. Sections were mounted onto chrome-alum gelatin-coated slides, dehydrated, and coverslipped. The same immunohistochemistry procedures described above were followed for total TH. Positive nuclei for c-Fos immunoreactivity were detected using conventional light microscopy and counted at $\times 20$ magnification. c-Fos-positive $\mathrm{TH}$ positive neurons were identified as cells with brown cytoplasmic deposits for TH-positive staining and blue/dark nuclear staining for c-Fos. A square field $(129 \mu \mathrm{m})$ was superimposed on captured image for using as reference area. The number of single- and double-labeled c-Fos neurons observed bilaterally was counted in four to six sections from each animal in the VTA.

\section{References}

1. Koob GF (2008) A role for brain stress systems in addiction. Neuron 59: 11-34.

2. Piazza PV, Le Moal M (1998) The role of stress in drug self-administration. Trends Pharmacol Sci 19: 67-74.

3. Sinha R (2008) Chronic stress, drug use, and vulnerability to addiction. Ann N Y Acad Sci 1141: 105-130.

4. Goeders NE, Guerin GF (2000) Effects of the CRH receptor antagonist CP154,526 on intravenous cocaine self-administration in rats. Neurophsychopharmacology 23: 577-586.

5. Piaza PV, Le Moal ML (1996) Pathophysiological basis of vulnerability to drug abuse: Role of an interaction between stress, glucocorticoids, and dopaminergic neurons. Annu Rev Pharmacol Toxicol 36: 359-378.
Figure 6 shows the experimental protocol used in the study.

\section{Drugs and Chemicals}

Pellets of morphine base (Alcaliber Laboratories, Madrid, Spain) or lactose were prepared by the Department of Pharmacy and Pharmaceutic Technology (School of Pharmacy, Granada, Spain); sodium dodecylsulphate, polyacrylamide gel and PVDF membranes were obtained from Bio-Rad Laboratory (Teknovas, Bilbao, Spain); goat serum (Sigma Adrich, St. Louis, MO) and nickel sulfate (Sigma Adrich). Naloxone $\mathrm{HCl}$ was dissolved in sterile $0.9 \% \mathrm{NaCl}$ (saline). CP-CP-154,526 (Sigma-Adrich) was dissolved in 10\% Tween 80 (Sigma-Adrich). Drugs were prepared fresh every day.

\section{Statistical analysis}

The results are expressed as the mean \pm S.E.M. using the GraphPad Prism statistical package. Body weight loss, and hormonal and biochemical parameters were analyzed by twoway analysis of variance (ANOVA) with pretreatment (placebo, morphine) and acute treatment (vehicle, CP-154,526) as independent variables. Newman-keuls post-hoc test was used for individual comparisons. Body weight gain in naive and morphine dependent rats were analysed by unpaired student's $t$-test. behaviours were quantified as the number of animals exhibiting the sign/total number of animals observed and data obtained were analyzed non-parametrically using the $\mathrm{x}^{2}$ test differences with a $\mathrm{p}$ value less than 0.05 were considered significant.

\section{Author Contributions}

Conceived and designed the experiments: MLL. Performed the experiments: JNZ JAGC LM JH. Analyzed the data: PA MVM MLL. Contributed reagents/materials/analysis tools: PA JAGC JH. Wrote the paper: PA MLL.

6. Delfs JM, Zhu Y, Druhan JP, Aston-Jones G (2000) Noradrenaline in the ventral forebrain is critical for opiate withdrawal-induced aversion. Nature 403: 430434.

7. Rodriguez de Fonseca F, Carrera MR, Navarro M, Koob GF, Weiss F (1997). Activation of corticotropin-releasing factor in the limbic system during cannabinoid withdrawal. Science 276: 2050-2054.

8. Van Pett K, Viau V, Bittencourt JC, Chan RK, Li HY, et al. (2000) Distribution of mRNAs encoding CRF receptors in brain and pituitary of rat and mouse. J Comp Neurol 428: 191-212.

9. Korossi A, Veening JG, Kozicz T, Henckens M, Dederen J, et al. (2006) Distribution and expression of CRF receptor 1 and 2 mRNAs in the CRF overexpressing mouse brain. Brain Res 1072: 46-54. 
10. Koob GF (2010) The role of CRF and CRF-related peptides in the dark side of addiction. Brain Res 1314: 3-14.

11. Laorden ML, Fuertes G, González-Cuello A, Milanés MV (2000) Changes in catecholaminergic pathways innervating paraventricular nucleus and pituitaryadrenal axis response during morphine dependence: Implication of alphal and alpha2 adrenoreceptors. J Pharmacol Exp Ther 293: 578-584.

12. Laorden ML, Nuñez C, Almela P, Milanés MV (2002) Morphine withdrawalinduced c-Fos expression in the hypothalamic paraventricular nucleus is dependent on the activation of catecholaminergic neurones. J Neurochem 83: 132-140.

13. Koob GF (1999) Corticotropin-releasing factor, norepinephrine, and stress. Biol Psychiatry 46: 1167-1180.

14. Stinus L, Cador M, Zorrilla EP, Koob GF (2005) Buprenorphine and GRF1R antagonists block the acquisition of opiate withdrawal-induced conditioned place aversion in rats. Neuropsychopharmacology 30: 90-98.

15. Carlezon WA, Thomas MJ (2009) Biological substrates of reward and aversion: A nucleus accumbens activity hypothesis. Neurophamacology 56: 122-132.

16. Koob GF, Le Moal M (2001) Drug addiction, dysregulation of reward, and allostasis. Neuropsychopharmacology 24: 97-129.

17. Di Chiara G, North AR (1992) Neurobiology of opiate abuse. Trends Pharmacol Sci 13: 185-193.

18. Roesch MR, Galu DJ, Schoenbaum G (2007) Dopamine neurons encode the better option in rats deciding between differently delayed or sized rewards. Nat Neurosci 10: 1615-1624.

19. Schultz W (2007) Multiple dopamine functions at different time courses. Annu Rev Neurosci 30: 259-288.

20. Matsumoto M, Hikosaka O (2009) Two types of dopamine neuron distinctly convey positive and negative motivational signals. Nature 459: 837-841.

21. Sinha R (2001) How does stress increase risk of drug abuse and relapse? Psychopharmacology (Berl) 158: 343-359.

22. Erb S, Shaham Y, Stewart J (1996) Stress reinstates cocaine seeking behaviour after prolonged extinction and a drug-free period. Psychopharmacology (Berl) 128: 408-412.

23. Abercrombie ED, Keefe KA, DiFrischia DS, Zigmond MJ (1989) Differential effect of stress on in vivo dopamine release in striatum, nucleus accumbens, and medial frontalcortex. J Neurochem 52: 1655-1658.

24. Inglis FM, Moghaddam B (1999) Dopaminergic innervations of the amygdala is highly responsive to stress. J Neurochem 72: 1088-1094.

25. McFarland K, Davidge SB, Lapish CC, Kalivas PW (2004) Limbic and motor circuitry underlying footshock-induced reinstatement of cocaine-seeking behaviour. J Neurosci 24: 1551-1560.

26. Tidey JW, Miczek KA (1996) Social defeat stress selectively alters mesocorticolimbic dopamine release: an in vivo microdialysis study. Brain Res 721: 140149 .

27. Wang B, Shaham Y, Zitzman D, Azari S, Wise RA, et al. (2005) Cocaine experience establishes control of midbrain glutamate and dopamine by corticotrophin-releasing factor: a role in stress -induced relapse to drug seeking. J Neurosci 25: 5389-5396.

28. Wanat MJ, Hofp EW, Stuber GD, Phillips PEM, Bonci A (2008) Corticotropinreleasing factor increases mouse ventral tegmental area dopamine neuron firing through a protein kinase C-dependent enhancement of Ih. J Physiol 586: 21572170 .

29. Nuñez C, Földes A, Pérez-Florez D, García-Borrón JC, Laorden ML, et al. (2009) Elevated glucocorticoid levels are responsible for induction of tyrosine hydroxylase (TH)mRNA expression, phosphorylation and enzyme activity in the nucleus of the solitary tract (NTS-A2) during morphine withdrawal. Endocrinology 150: 3118-3127.

30. Gallagher JP, Orozco-Cabal LF, Liu J, Shinnick-Gallagher P (2008) Synaptic physiology of central CRH system. Eur J Pharmacol 583: 215-225.

31. Zorrilla EP, Koob GF (2004) The therapeutic potential of CRF1 antagonists for anxiety. Expert Opin Investig Drugs 13: 799-828.

32. Contarino A, Papaleo F (2005) The corticotropin-releasing factor receptor-1 pathway mediates the negative affective states of opiate withdrawal. Proc Natl Acad Sci USA 102: 18649-18654.

33. Navarro-Zaragoza J, Nuñez C, Laorden ML, Milanés MV (2010) Effects of corticotrophin-releasing factor receptor-1 antagonists on the brain stress system responses to morphine withdrawal. Mol Pharmacol 77: 864-873.

34. Papaleo F, Kitchener P, Contarino A (2007) Disruption of the CRF/CRF1 receptor stress system exacerbates the somatic signs of opiate withdrawal. Neuron 53: 577-589.

35. Fuertes G, Laorden ML, Milanés MV (2000) Noradrenergic and dopaminergic activity in the hypothalamic paraventricular nucleus after naloxone-induced morphine withdrawal. Neuroendocrinology 71, 60-67.

36. Nuñez C, Castells MT, Laorden ML, Milanés MV (2008) Regulation of extracellular signal-regulated kinases (ERKs) by naloxone-induced morphine withdrawal in the brain stress system. Naunyn-Schmiedeberg's Arch Pharmacol $378,407-420$.

37. Skelton KH, Oren D, Gutman DA, Easterling K, Holtzman SG, et al. (2007) The CRF1 receptor antagonist, R121919 attenuates the severity of precipitated morphine withdrawal. Eur J Pharmacol 571: 17-24.

38. Zobel AW, Nickel T, Küazel HE, Ackl N, Sonntag A, et al. (2000) Effects of the high-affinity corticotrophin-releasing hormone receptor 1 antagonist R121919 in major depression: the first 20 patients treated. J Psychiatr Res 34: 171-181.
39. Tilders FJ, Berkenbosch F, Vermes I, Linton EA, Smelek PG (1985) Role of epinephrine and vasopressin the control of the pituitary-adrenal response to stress. Fed Proc 44: 155-168.

40. Deak T, Nguyen KT, Ehrlich AL, Watkins LR, Spencer RL, et al. (1999) The impact of the nonpeptide corticotrophin-releasing hormone antagonist antalarmin on behavioural and endocrine responses to stress. Endocrinology 140: 79-86.

41. Leknes S, Tracey I (2008) A common neurobiology for pain and pleasure. Nat Rev Neurosci 9: 314-320.

42. Montague PR, Hyman SE, Cohen JD (2004) Computational roles for dopamine in behavioural control. Nature 431: 760-767.

43. Schultz W (1998) Predictive reward signal of dopamine neurons. J Neurophysiol 80: $1-27$.

44. Ungless MA (2004) Dopamine: the salient issue. Trends Neurosci 27: 702-706.

45. Ungless MA, Magill PJ, Bolam JP (2004) Uniform inhibition of dopamine neurons in the ventral tegmental area by aversive stimuli. Science 303: 20402042.

46. Brischoux F, Chakraborty S, Brierley DI, Ungless MA (2009) Phasic excitation of dopamine neurons in ventral VTA by noxious stimuli. Proc Natl Acad Sci USA 106: $4894-4899$.

47. Wang DV, Tsien JZ (2011) Convergent processing of both positive and negative motivational signals by the VTA dopamine neuronal populations. PLoS One 6: e17047

48. Zweifel LS, Fadok JP, Argilli E, Garelick MG, Jones GL, et al. (2011) Activation of dopamine neurons is critical for aversive conditioning and prevention of generalized anxiety. Nat. Neurosci. 14: 620-626.

49. Budygin EA, Park J, Bass CE, Grinevich VP, Bonin KD, et al. (2012) Aversive stimulus differentially triggers subsecond dopamine release in reward regions. Neurosci 201: 331-337.

50. Rosseti ZL, Hmaidan Y, Gessa GL (1992) Marked inhibition of mesolimbic dopamine release: a common feature of ethanol, morphine, cocaine and amphetamine abstinence in rats. Eur J Pharmacol 221: 227-234.

51. Diana M, Pistis M, Muntoni A, Gessa G (1995) Profound decrease of mesolimbic dopaminergic neuronal activity in morphine-withdrawn rats. J Pharmacol Exp Ther 272: 781-785

52. Mazei-Robison MS, Koo JW, Friedman AK, Lansink CA, Robison AJ, et al. (2011) Role for mTOR signalling and neuronal activity in morphine-induced adaptations in ventral tegmental area dopamine neurons. Neuron 72: 977-990.

53. Sauvage M, Steckler T (2001) Detection of corticotrophin-releasing hormone receptor 1 immunoreactivity in cholinergic, dopaminergic and noradrenergic neurons of the murine basal forebrain and brainstem nuclei: potential implication for arousal and attention. Neuroscience 104: 643-652.

54. Smith RJ, Aston-Jones G (2008) Noradrenergic transmission in the extended amygdale: role in increased drug-seeking and relapse during protracted drug abstinence. Brain Struct Funct 213: 43-61.

55. Aston-Jones G, Kalivas PW (2008) Brain norepinephrine rediscovered in addiction research. Biol. Psychiatry 63: 1005-1006.

56. Garcia-Carmona JA, Almela P, Baroja-Mazo A, Milanés MV, Laorden ML (2011) Restricted role of CRF1 receptor for the activity of brainstem catecholaminergic neurons in the negative state of morphine withdrawal. Psychopharmacology 220: 379-393.

57. Dunkley PR, Bobrovskaya L, Graham ME, von Nagy-Felsobuki EI, Dickson PW (2004) Tyrosine hydroxylase phosphorylation: regulation and consequences. J Neurochem 91: 1025-1043.

58. Lu L, Liu Z, Huang M, Zhang Z (2003) Dopamine-dependent responses to cocaine depend on corticotrophin-releasing factor receptor subtypes. J Neurochem 84: 1378-1386.

59. Salvatore MF, García-España A, Goldstein M, Deutch AY, Harykock JW (2000) Stoichiometry of tyrosine hydroxylase phosphorylation in the nigrostriatal and mesolimbic systems in vivo: effects of acute haloperidol and related compounds. J Neurochem 75: 225-232.

60. Riegel AC, Williams JT (2008) CRF facilitates calcium release from intracellular stores in midbrain dopamine neurons. Neuron 57: 559-570.

61. Ungless MA, Singh V, Crowder TL, Yaka R, Ron D, et al. (2003) Corticotropinreleasing factor requires $\mathrm{CRF}$ binding protein to potentiate NMDA receptors via CRF receptor 2 in dopamine neurons. Neuron 39: 401-407.

62. Frenois F, Cador M, Caille S, Stinus L, Moine C (2002) Neural correlation of the motivational and somatic components of naloxone-precipitated morphine withdrawal. Eur J Neurosci 16: 1377-1389.

63. Gold LH, Stinus L, Inturrisi CE, Koob GF (1994) Prolonged tolerance, dependence, and abstinence following subcutaneous morphine pellet implantation in the rat. Eur J Pharmacol 253: 45-51.

64. Berhow MT, Russel DS, Terwilliger RZ, Beitner-Johnson D, Self DW, et al. (1995) Influence of neurotrophic factors on morphine - and cocaine-induced biochemical changes in the mesolimbic dopamine system. Neurosci 68: 969979.

65. Wiechelman KJ, Braun RD, Fitpatrick JD (1988) Investigation of the bicinchoninic acid protein assay: identification of the groups responsible for color formation. Anal Biochem 175: 231-237.

66. Nuñez C, Laorden ML, Milanés MV (2007) Regulation of Serine (Ser)-31 and Ser40 tyrosine hydroxylase phosphorylation during morphine withdrawal in the hypothalamic paraventricular nucleus and nucleus tractus solitarius-A2 cell group. Role of ERK1/2. Endocrinology 148: 5780-5793. 